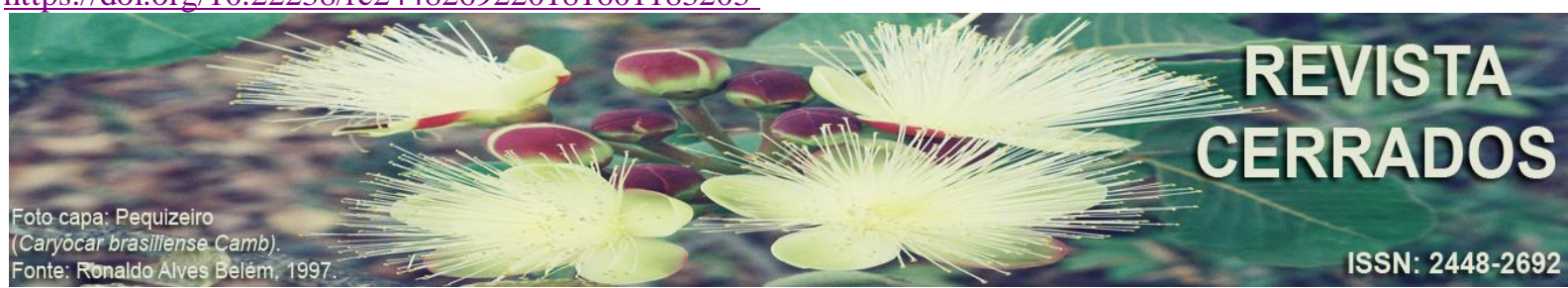

\title{
DIVERSIDADES E DIREITOS TERRITORIAIS NO SEMI-ÁRIDO ${ }^{1}$
}

\section{DIVERSITY AND TERRITORIAL RIGTHS IN SEMI-ARID}

\section{DIVERSITÉS ET DROITS TERRITORIAUX DANS LE SEMI-ARIDE}

\author{
João Batista de Almeida Costa \\ Universidade Estadual de Montes Claros - UNIMONTES \\ E-mail: <joba.costa@unimontes.br>.
}

\begin{abstract}
RESUMO
Objetivando discutir sobre as diversidades e direitos territoriais no Semi-árido brasileiro, baseado em estudos de caso, realizo uma leitura sobre as raízes históricas de formação das diferentes etnias e da constituição de territórios nessa região para em seguida fazer uma digressão sobre as bases legais que alicerçam o direito à diversidade. É realizada, também, uma abordagem sobre as bases conceituais para o entendimento da emergência de sujeitos coletivos que buscam concretizar os direitos territoriais por meio da visibilização de suas gentes a partir da auto-afirmação de si em suas territorialidades. Para finalizar é focalizada a fricção de interesses territoriais entre as camadas superior e inferior da sociedade nacional que opõem diversidade de lógica de apropriação x mercantilidade com casos de gentes do Nordeste do Brasil e do Norte de Minas Gerais. E, nesse caso, elenco as estratégias de concretização do direito territorial de comunidades tradicionais norte mineiras.
\end{abstract}

Palavras Chaves: Diversidade. Direitos Territoriais. Semi-árido

\begin{abstract}
Aiming to discuss territorial diversity and rights in the brazilian semi-arid region, based on case studies, I make a reading about the historical roots of formation of the different ethnic groups and the constitution of territories in this region and then digress on the legal bases that underpin the right to diversity. It is also carried out an approach on the conceptual bases for the understanding of the emergence of collective subjects that seek to concretize the territorial rights through the visibility of its people from the self-affirmation of themselves in their territorialities. Finally, the friction of territorial interests between the upper and lower strata of the national society that opposes the diversity of appropriation and mercantile logic with cases

\footnotetext{
${ }^{1}$ Originalmente apresentado na abertura do VII Workshop Nacional em Educação Contextualizada para a Convivência com o Semi-árido Brasileiro e do IV Colóquio de Pós-Graduação do Vale do São Francisco em Juazeiro: 30/08/2017.
} 
of people from Northeast Brazil and Northern Minas Gerais is focused. And, in this case, cast strategies for the realization of the territorial law of traditional norte mineiras communities.

Key Words: Diversity. Territorial rights. Semi-Arid.

\section{RESUMÉE}

Sur la base d'études de cas, viser une discussion sur les origines historiques de la formation des différents groupes ethniques et des constitutions territoriales dans cette région semi-aride brésilienne a été consacrée à la discussion de la diversité et des droits territoriaux dans la région est faite et ensuite la digression sur les bases juridiques qui soutenir le droit à la diversité. Une approche est également menée sur les bases conceptuelles pour la compréhension de l'émergence de sujets collectifs qui cherchent à concrétiser les droits territoriaux par la visibilité de leur peuple par affirmation d'eux-mêmes dans leurs territoires. Enfin, la friction des intérêts territoriaux entre les strates supérieure et inférieure de la société nationale qui s'oppose à la diversité de la logique d'appropriation et à la mercantilité à travers les cas du peuple du Nord-Est du Brésil et du Nord de Minas est concentrée. Et, dans ce cas, énumérez les stratégies pour la réalisation de la loi territoriale des communautés minières traditionnelles du Nord.

Mots Clés: Diversité. Droits Territoriaux. Semi-Aride.

\section{INTRODUÇÃO}

O Semi-árido no Brasil possui uma longa historicidade de construção de territorialidades diferenciadas pelos inúmeros grupos humanos que nele se fixaram e organizaram suas vidas na relação com a ecologia de cada espaço onde constituíram suas coletividades. Neste artigo tendo como temática os direitos territoriais e as diversidades étnicas faço, pela utilização de estudos de caso sobre processos sociais de disputas territoriais em comunidades rurais, uma pequena abordagem da emergência dessas gentes como sujeitos de direito na Constituição de 1988. Faço um pequeno percurso na conceituação teórica que propicia realizar a leitura dos dramas sociais vividos por essas gentes. Em seguida, por meio de um olhar abrangente focalizo, neste artigo, as etnicidades que emergiram na região semi-árida reivindicando direitos territoriais coletivos por fundamentarem a construção política de diversos grupos que se compreendem, alicerçados no texto constitucional, como grupos formadores da nacionalidade brasileira. E, por fim, apresento as estratégias que comunidades norte mineiras ao afirmarem, pela politização de suas identidades étnicas, suas tradicionalidades, concretizam de forma articulada, suas lutas por direitos territoriais. 


\section{A historicidade da diversidade étnica e de territorialidade no Semi-Árido}

Por uma poética desses processos, enuncio a partir da memória essas palavras cantadas por Luiz Gonzaga, o menestral nordestino: Juazeiro, Juazeiro, me arresponda por favor... Juazeiro, meu destino tá ligado junto ao teu. Digo isto porque falar de diversidade e direitos em territórios do Semi-árido é falar de todos que têm o Rio São Francisco como a veia por onde transitou tanta gente, tanta cultura, tanta história, tanta luta e a construção de um Brasil verdadeiramente diverso. Pois como escreveu Euclides da Cunha (2015) somos: $O$ cerne da nação! E que para assim o ser, necessita, como nos narrou Guimarães Rosa (1986, p. 83): da gã que empurra a gente para fazer tantos atos, dar corpo ao suceder.

Nesse espaço, denominado pela geografia como Semi-árido brasileiro, primordialmente existiram dezenas de sociedades indígenas que, bravamente, lutaram contra a colonização portuguesa, como evidenciado na guerra contra a confederação dos Kariri no final do século XVII. Nele adentraram africanos que ao aportarem e terem a possibilidade da fuga internaram-se pelas desconhecidas terras da colônia Brasil e fundaram centenas de pequenos aquilombamentos invisibilizados para poderem usufruir da autonomia e liberdade. Tão distintos do conjunto de povoações que formaram o Quilombo de Palmares destruído pelas mesmas tropas que deram fim à articulação de vinte e sete grupos indígenas do Semiárido nordestino liderados pelos Kariri.

A penetração da colonização portuguesa ocorreu em meio a duas dinâmicas distintas: a primeira a imposição do branco sobre o negro da terra e o negro africano sob a égide da organização administrativa colonial. E a segunda, o encontro de gentes, de culturas, dando corpo a suceder diferenciados, das gentes miúdas, denominadas no período de os desclassificados (SOUZA, 1986). Essas duas dinâmicas se imbricaram e por um longo período viveram processos distintos e colaborativos, por um lado, uma camada de mando e por outro, como afirma Costa Silva (1998), o manejo de um território não-branco. Com a Lei da Terra em 1850 instauram-se as raízes, que no século XX, colocam definitivamente em oposição e confronto essas duas dinâmicas, por um lado a mercantilização da terra com financiamentos pelo Estado e por outro a luta pelos territórios da diversidade com lógicas de apropriação em articulações diferenciadas entre si e com aqueles que lhes conferem uma razão histórica na construção de uma sociedade mais equânime e menos perversa. 
Essas duas dinâmicas desaguaram seus projetos de nação durante o processo constituinte que dispôs no texto constitucional as bases da sociedade brasileira sonhada por todos aqueles que a projetam como uma possibilidade de ser uma civilização nova, como afirmava peremptoriamente Darcy Ribeiro (1995). No momento atual vive-se no Brasil os temerosos tempos do rasgamento desse texto por parte daqueles que deveriam defendê-lo, mas há resistências dos sujeitos históricos que lutam por direitos equânimes.

\section{As bases legais que alicerçam direitos da diversidade histórica das gentes miúdas}

Em termos constitucionais, ficou disposto no capítulo sobre a Ordem Social da Constituição Federal de 1988, a plena garantia dos direitos culturais e a proteção aos bens de natureza material e imaterial portadores de referência à identidade, à ação, à memória dos diferentes grupos formadores da sociedade brasileira, dentre eles os modos de criar, fazer e viver. Como direitos emergentes (ARRUTI, 1997), essas disposições constitucionais inventam sujeitos de direito coletivos alargando a ordem jurídica nacional, para tornar persona jurídica esses sujeitos diversos espalhados no território nacional cuja razão histórica (LITTLE, 2005) se opõe desde a colônia à razão instrumental do Estado-Nação sempre amparado pelas legislações nascidas das alianças das elites regionais.

Esses sujeitos coletivos emergentes não tiveram garantido efetivamente na Constituição de 1988 qualquer direito, uma vez que os sujeitos e os objetos desse direito não foram determinados. Quem são e onde se encontram esses grupos partícipes do processo civilizatório nacional possuidores de referências que devem ter garantidos o pleno exercício de sua identidade, ação e memória pelos modos de criar, fazer e viver?

Posto idealmente o direito, os grupos que se compreendem vinculados a esses sujeitos de direito, dão partida a um processo de (des)invisibilização mostrando suas caras, seus jeitos de criar, fazer e viver por todos os rincões do território brasileiro, em dinâmicas de lutas articuladas por grupos rurais e urbanos pelo reconhecimento de direitos relativos à diferença. Em sua tese sobre o caminho quilombola Figueiredo (2011) considera que esta luta é entendida a partir de um modelo de ação coletiva no qual o desrespeito a uma determinada forma de ser no mundo enseja um conflito cujo principal resultado é a evolução moral da sociedade (FIGUEIREDO, 2011, p. 30-31, grifos no original). 
Esse autor aproxima-se do entendimento de que as lutas por reconhecimento buscam a "condição para que o sujeito mantenha uma relação de integridade consigo", como teorizado por Axel Honneth (2003) que considera serem as lutas de reconhecimento constituídas por relações afetivas que tratam da autonomia corporal, das relações jurídicas que implicam no reconhecimento da condição de sujeito de direito. E, por fim, das relações comunitárias que enfatizam o respeito que os sujeitos devem ter sobre seu modo de ser sob pena de ofender a honra das comunidades que têm vinculadas a si o direito constitucional disposto nos artigos 215 e 216 que propiciou a invenção jurídica, pelas gentes miúdas, as identidades que pluralizam a realidade social brasileira dada as suas emergências.

Os constituintes brasileiros construíram, em princípio, uma comunidade ética nacional na qual é preciso que haja respeito mútuo entre os indivíduos partícipes, assim como aos diferentes estilos de vida. Ao assim fazê-lo, conjugaram a afirmação da dignidade humana ao reconhecimento das particularidades culturais, consolidando não apenas a perspectiva normativa do comunitarismo liberal, mas particularmente sua vertente multiculturalista (FIGUEIREDO, 2011, p. 35).

Os constituintes em 1988, conforme afirmado por alguns estudiosos do direito constitucional, foram inspirados nos fundamentos que estavam sendo organizados para as definições da Convenção 169 da Organização Internacional do Trabalho, de 1989, que propôs a todas as nações do planeta o respeito aos direitos dos povos coletivos vigentes no interior das nacionalidades. Esses fundamentos compartilhados pelos constituintes propiciaram a construção dos marcos legais que inventaram os novos sujeitos de direito coletivo no Brasil. E, por outro lado, a multiplicidade de grupos sociais que emergiram amparados nos princípios constitucionais que alicerçam a sociedade brasileira. Ao se tornarem visíveis e reivindicarem para si o reconhecimento de suas diferenças impõem ao Estado-Nação a construção de mecanismos, processos e políticas públicas capazes de atenderem às reivindicações de mulheres e homens que se erguem em todo o território nacional. E por meio de lutas sociais, jurídicas e políticas constroem politicamente suas identidades diferenciadas.

O ponto crucial do acesso a direitos específicos diz respeito à produção política de identidade $^{2}$, baseada em práticas, saberes e manifestações culturais para a afirmação territorial de povos e comunidades tradicionais dada a emergência de grupos sociais reivindicando-se

\footnotetext{
${ }^{2}$ Para ampliar a compreensão sobre o processo político de construção de identidade vide Silva (2000). 
COSTA, J. B. A.

Diversidades e direitos territoriais no semi-árido

como sujeitos de direito desde a promulgação da Constituição Federal de 1988. Se o princípio constituinte e constitutivo desses sujeitos de direito emergente alicerça-se na cultura e na identidade de cada um dos povos e das comunidades existentes no Brasil, entre o direito e a prática existem diversos obstáculos que requerem de cada comunidade inserir-se em um processo de (des)invisibilidade para estabelecer o vínculo de si mesma como sujeito coletivo do direito constitucional ${ }^{3}$.

Em legislação infraconstitucional o governo federal criou pelo Decreto de 27 de dezembro de 2004 e modificado pelo Decreto de 13 de julho de 2006 A Comissão Nacional de Desenvolvimento Sustentável dos Povos e Comunidades Tradicionais, com caráter deliberativo e consultivo, constituída por representantes de órgãos e entidades federais e de organizações não governamentais. Resulta de sua atuação a instituição da Política Nacional de Desenvolvimento Sustentável de Povos e Comunidades Tradicionais tendo como principal objetivo a promoção do desenvolvimento sustentável desses grupos com ênfase no reconhecimento, fortalecimento e garantia dos seus direitos territoriais, sociais, ambientais, econômicos e culturais, respeitando e valorizando suas identidades, formas de organização e instituições.

No decreto 6.040/2007 é considerado que os grupos sociais formadores da nacionalidade brasileira

grupos culturalmente diferenciados e que se reconhecem como tais, que possuem formas próprias de organização social, que ocupam e usam territórios e recursos naturais como condição para sua reprodução cultural, social, religiosa, ancestral e econômica, utilizando conhecimentos, inovações e práticas gerados e transmitidos pela tradição (BRASIL, 2007).

E definiu como territórios tradicionais “os espaços necessários à reprodução cultural, social e econômica dos povos e comunidades tradicionais, sejam eles utilizados de forma permanente ou temporária" (BRASIL, 2007).

Sociedades indígenas e comunidades remanescentes de quilombo têm no texto constitucional o direito ao território tradicionalmente ocupado enquanto os grupos étnicos que lutam por suas territorialidades não estão nele explicitamente cobertos. Na ótica dessas gentes miúdas a garantia do modo de criar, fazer e viver só pode ser assegurado pelo acesso

\footnotetext{
${ }^{3}$ Discuti em Costa (2011) a compreensão das dinâmicas e estratégias para a eficácia de um processo de (des)invisibilização de Povos e Comunidades Tradicionais.
} 
permanente ou temporário ao espaço territorial onde inscrevem sua historicidade como grupo formador da nacionalidade brasileira. A permanência ou transitoriedade é dependente da especificidade de cada tradicionalidade. E, para tanto, procuram e encontram brechas para concretizarem o que consideram seus direitos e por aí, resistem ativamente em suas lutas coletivas.

Para tanto, cada povo ou cada comunidade para ser considerada tradicional e ser efetivamente partícipe do direito de que são detentores necessita produzir-se culturalmente como tal e afirmar-se em sua territorialidade que fundamenta o sentido de pertencimento ao sujeito coletivo de que são constitutivos. Ainda que exista legislação supraconstitucional, constitucional e infraconstitucional, há diversas amarras que os mantêm invisíveis aos olhos do Estado e da Sociedade Nacional que necessitam ser desarticuladas para que se visibilizem no campo político de produção de suas legitimidades como portadores efetivos de direito ${ }^{4}$.

\section{A refração do olhar: as bases conceituais para o entendimento do direito territorial}

Direito territorial coletivo, insurge constitucionalmente no padrão agrário brasileiro vigente até 1988 , dado que o mesmo

remete-nos à ideia de Direitos culturais, uma vez que tais direitos também expressam as formas de vida, nos seus modos de "criar, fazer e viver" (Art. 216, II, CF/1988). Extrai se um primeiro sentido, o de que, a expressão cultural, territorialmente manifestada assume um papel constituinte e fundamental nas coletividades dos povos originários e tradicionais (CHAGAS, 2017, P. 185).

A fundamentação jurídica dos direitos territoriais coletivos ampara-se em estudos antropológicos que foram desenvolvidos em grupos étnicos por todo o planeta e que abordaram leituras territoriais sendo o foco colocado na em busca da compreensão de uma razão histórica que fundamenta o sentido de pertencimento e o caráter solidário do território com a identidade de cada um dos grupos estudados. Essa perspectiva etnográfica propicia afirmar que não há identidade étnica sem território e que nas cosmografias de cada situação em estudo emerge a compreensão da oposição à razão instrumental dos Estados-Nações, neste sentido vide a tematização de Little (2005) em seu estudo por uma antropologia da territorialidade. Essa percepção construída na Antropologia opõe-se a outras percepções

\footnotetext{
${ }^{4}$ Faço em Costa (2015) a discussão sobre as amarras que os mantiveram invisíveis. 
disciplinares que vincularam o território, apenas, às sociedades nacionais. Outros tempos, outros lugares, outros olhares.

A razão histórica do território evidencia que, para além da terra para a produção, há as dimensões simbólicas e que "um território surge diretamente das condutas de territorialidade de um grupo social [e] implica que qualquer território é um produto histórico de processos sociais e políticos" (LITTLE, 2005, p. 254). No território estão impressos os acontecimentos ou fatos históricos que mantêm viva a memória de um determinado do grupo; estão enterrados os ancestrais e encontram-se os sítios sagrados; ele determina o modo de vida e a visão de homem e de mundo. O território é também apreendido e vivenciado a partir dos sistemas de conhecimento locais, ou seja, não há povo ou comunidade tradicional que não reconheça seu território.

O território enseja um sentimento de pertença, não somente pela relação visceral que se estabelece com o grupo, mas também pelas condutas de territorialidade, o que comumente envolve mobilização continuada no sentido da demarcação e defesa, critérios de inclusão e exclusão, identificação com um bioma / ecossistema. Nessa perspectiva não estão considerados os povos cujos territórios foram expropriados e se refugiaram no plano da memória, os povos nômades e transumantes e, por fim, as comunidades que foram engolidas pelas cidades. Neste último caso, através de uma hierarquização simbólica, a construção do território englobado na malha urbana como uma região moral, na perspectiva de Park (1948), tem imputada a si características distintivas e inferiorizantes que a desqualifica e à população que nela habita. Muitas vezes nasce dessa hierarquização tanto a evitação nos deslocamentos pelas vias urbanas, quanto o horror do contato humano com sua gente.

No território há sempre uma noção de pertencimento a um lugar específico que é nosso e que propicia a construção de várias condutas de territorialidade. É pela localização dos grupos sociais em um ecossistema específico na contrastividade com outros grupos que se constrói identidades ecológicas (PARAJULI, 1996), dado que o manejo do território é vinculado à ecologia onde determinado grupo culturalmente diferenciado reproduz física, social e culturalmente a si mesmo. Na fricção entre grupos situados em ecologias distintas, as identidades ecológicas são politicamente nomeadas, como caatingueiro, geraizeiro, por exemplo.

Assim, o manejo produtivo em contextos tradicionais necessário à reprodução de cada grupo social está na contramarcha do agronegócio e voltada, prioritariamente, para a 
troca com reciprocidade, para a manutenção da coesão social. O sistema produtivo tem lógica e ritmo próprios, sendo as relações produtivas baseadas na unidade doméstica familiar e entranhada na unidade coletiva de que se faz parte. A comercialização para o mercado não é o único fim da produção, dado que o objetivo último é a reprodução do próprio grupo, sendo parte dela destinada ao consumo e parte às práticas sociais, como as festas, os ritos, as procissões, as folias de reis, etc. Neste sentido, não há como não reconhecer, ali, a sobreposição do calendário religioso e agrícola. Por fim, nesses tempos de preocupações ambientais, é recorrente o uso comunitário de recursos naturais renováveis utilizando tecnologias de baixo impacto ambiental, resultando no fato de que esses grupos se constituem em guardiões da agrobiodiversidade.

Em termos de organização social, é possível encontrar distintas modalidades de família com predominância da família extensa ou ampliada na organização da comunidade que mantém inter-relações com outros grupos similares na região, por meio de encontros, festas, casamentos, etc. Cada comunidade se define e se constrói por contraposição a outros segmentos ou grupos sociais da região visto que existem termos utilizados pelos seus membros para se referir ao seu próprio grupo, se auto-identificando. Cabe notar que são frequentes as cisões e facções políticas internas no grupo, decorrente de tensões intrasocietárias. E ocorrem tensões inter-societárias com grupos sociais, povos e comunidades que são considerados concorrentes ou opositores tradicionais. Em muitos grupos étnicos, a unidade sociocultural transcende o recorte municipal, estadual e nacional, quando se reconhece a sua distribuição demográfica tradicional.

Em termos de institucionalidade tradicional, há múltiplas formas de organização que são constituídas muito antes das associações e cooperativas evidenciando o protagonismo social das comunidades que deve ser considerada nas intervenções externas pela participação nas instâncias de controle social.

Do ponto de vista da cultura, há expressões culturais próprias: expressões linguísticas, festas, rezas, comidas, modo de fazer as casas, roupas, etc. E em outra dimensão, mitos e ritos associados às atividades produtivas da pesca, da caça, do extrativismo, do plantio e da criação de animais. Os conhecimentos culturais e ambientais são transmitidos de forma oral de geração em geração, daí a grande importância dos anciões, que são os guardiões da memória do grupo. 


\section{A fricção dos interesses territoriais: diversidade $\mathbf{x}$ mercantilidade}

Ao olhar a questão territorial no espaço do Semi-árido duas lógicas saltam à vista, por um lado, embasada na razão histórica, a luta pela permanência no território de pertencimento e, por outro lado, a razão instrumental da mercantilidade da terra. Entre estas duas lógicas diversas dinâmicas têm sido manuseadas pelos povos e comunidades tradicionais.

Em termos constitucionais os indígenas e os quilombolas têm disposição jurídica claramente definida ao direito territorial, por estarem localizados em terras tradicionalmente ocupadas, que para Almeida (2004, p.9) "expressam uma diversidade de formas de existência coletiva de diferentes povos e grupos sociais em suas relações com os recursos da natureza". Agrega-se a eles, a emergência de grupos sociais reivindicando o direito coletivo à terra por serem partícipes da construção de nossa nacionalidade conforme disposto constitucional.

No escopo da emergência de novos sujeitos de direito coletivos na Constituição de 1988, são incorporadas as formas de apropriação dos recursos naturais baseadas no uso comum e os fatores culturais que colocam uma cunha no regime agrário brasileiro, desde sempre, vinculado, em propriedade privada, às elites administrativas, às oligarquias rurais e às empresas de agronegócio. As formas de uso comum alicerçam-se na lógica não-branca dos grupos subalternos, oposta à lógica eurocêntrica, capitalista e hegemônica da relação com a terra.

Dessa maneira, a emergência do direito coletivo coloca em colapso, pela possibilidade de manuseio privado e de sua mercantilização, a estrutura agrária privatista, dada a imprescritibilidade, a inalienabilidade e a indivisibilidade dos territórios dos povos e comunidades tradicionais.

No espaço do Semi-árido brasileiro há grupos sociais que emergiram reivindicando sua indianidade e rompendo com a invisibilidade que tinham assumido diante das formas com que foram tratados no decorrer da Colônia, do Império e da República brasileira. Seja pela tentativa de apagamento da indianidade nas missões coloniais, seja pelo reconhecimento de algumas sociedades no Império durante a vigência da Lei da Terra de 1850, ambas vinculadas a uma lógica de assimilação para transformá-los, naquilo que Darcy Ribeiro (1995), considerou: brasileiros de segunda classe. 
Outros grupos também emergem ao saírem de sua invisibilidade histórica construída para garantir autonomia e liberdade na produção e reprodução da vida, como as comunidades quilombolas. A formação dos quilombos durante o período escravista era uma forma de assumir o próprio destino de cada indivíduo aquilombado e, em sua maioria, estabeleceram relações estruturais com barreiras sociais e naturais que propiciavam vincularse a outros grupos sociais. Suas localizações preferenciais eram terras sem disputas para ocupação por seus acidentes geográficos ou suas insalubridades, dado que ninguém queria, para que pudessem garantir a reprodução de suas vidas dentro dos princípios que norteavam suas ações.

Outros grupos sociais se formaram a partir daquelas gentes consideradas desclassificadas coloniais, que negociaram suas fixações em sítios cujas condições de produção eram difíceis. Essa estratégia garantiu a permanência desses grupos na produção e reprodução da vida de cada família e das coletividades que se formaram por relações de parentesco e compadrio. São nascidos dessa dinâmica os caatingueiros ${ }^{5}$, os berradeiros e / ou ilheiros do Rio São Francisco e os que se denominam geraizeiros ${ }^{6}$ e fundo de pasto.

Transfiro meu olhar para outra parte do Semi-árido brasileiro, a porção norte mineira, pois é onde construo compartilhadamente estudos sobre as populações e comunidades que se afirmam tradicionais, para trazer a este momento alguns aprendizados da luta dessas gentes pela concretização do direito territorial. As estratégias articuladas podem ser consideradas como cruciais para iluminarem outros processos, que são dramas sociais na vida de todos os membros dessas comunidades.

As interpretações construídas são apoiadas em diversos estudos e pesquisas que têm como foco de leitura as territorialidades desses grupos e o assessoramento que diversos de pesquisadores fazemos a tantas comunidades étnicas norte mineiras. Discuti anteriormente (COSTA, 1997), que no sertão coexistem lógicas distintas de produção de espaços sociais e de territorialidades diversas. Como afirma Costa Silva (1998), desde os primórdios de ocupação territorial e da organização de uma sociedade específica, subjacente à lógica da expansão colonial ocorreu a produção de um espaço social branco que recobre todo o espaço

\footnotetext{
${ }^{5}$ Neste sentido vide Lopes (2012) que afirma a agonia da cultura dessa gente.

${ }^{6}$ Para maior conhecimento vide Rigato (2017) sobre processos vividos por comunidades rurais no vale do Rio Guará em São Desidério na Bahia.
} 
sertanejo no Brasil. No “interior dessa lógica, o território e o espaço social do 'outro', da alteridade radical do branco eram considerados virtualmente adstritos à etnia superior, eram embranquecidos, eram etnicizados" (COSTA SILVA, 1998, p. 3) e, portanto, não-branco.

As sociedades indígenas, as comunidades quilombolas e, posteriormente, as comunidades tradicionais surgidas na historicidade regional norte mineira desenvolveram e desenvolvem na atualidade resistências à lógica contrária de mercantilização da terra. Para o autor acima referenciado, estes grupos sociais, sendo outros, "opuseram uma lógica de resistência semelhante, mas oposta, construtora de uma territorialidade e de um espaço social não-brancos" (COSTA SILVA, 1998, p. 4). Nessa perspectiva, os espaços das populações tradicionais existentes no Sertão são considerados na teoria social brasileira como espaços não-brancos, apesar da lógica territorial branca que se coloca como hegemônica no espaço social sertanejo.

Como referido acima, um dos processos mais recentes que têm incidido sobre as populações tradicionais é concernente à problemática socioambiental, e se vincula crucialmente com a sobreposição de lógicas produtoras de espaços sociais e de territorialidades diferenciadas. Por um lado desenvolvidas pelas elites presentes no campo social e econômico regional e, por outro lado, ao Estado.

A ampliação de assimetria na hegemonização da lógica territorial branca ocorre a partir dos anos 1960, quando do processo de modernização da agricultura brasileira, pela concentração fundiária. Com a expansão das relações capitalistas de produção, as terras se mercantilizaram e as relações de trabalho assentadas, até então, em reciprocidade entre as categorias sociais distintamente situadas na estrutura social se transformaram em assalariamento com pagamento em numerário. Todavia, apesar da eficácia da lógica capitalista de produção de espaço social e territorial na construção de outra realidade socioeconômica, as populações tradicionais mantiveram suas lógicas distintas opondo-se à lógica das elites que tem se mantido hegemônica. Emerge neste cenário, o englobamento das lógicas contrárias que complexificaram as relações sociais no interior da estrutura social regional, ocorrendo complementaridade e, às vezes, oposição, no conjunto das lógicas construtoras de territorialidades e de espaços sociais distintos no sertão norte mineiro.

Atualmente, a assimetria na hegemonização da lógica territorial está apoiada em outro ator crucial que penetrou no campo das relações sociais sertanejas, o Estado, por meio das instituições de unidades de conservação, como parques nacionais ou estaduais e reservas 
biológicas, cujo princípio restritivo à presença humana tem conduzido a uma profunda desestruturação da reprodução da vida material e social de comunidades rurais, classificadas como tradicionais. Note-se que essas unidades de conservação que estão sendo instituídas e implantadas incidem exatamente nas áreas onde se localizam as populações tradicionais com suas práticas de preservação da natureza que secularmente vivenciam.

Há no espaço social norte mineiro, os chapadeiros, que vivem nas chapadas regionais, os campineiros, gentes que habitam as campinas, os barranqueiros e/ou vazanteiros que vivem e produzem nas barrancas ou vazantes do rio São Francisco. Há os geraizeiros, comunidades situadas nos gerais, há os veredeiros, essa gente das veredas e dos buritizais, há os caatingueiros e, emergindo no cenário atual, há os apanhadores de flores. E, claro, não podemos deixar de mencionar os indígenas: os Xakriabá e os Tuxá, bem como as dezenas de comunidades quilombolas espalhadas por todo espaço regional.

A lógica que orienta as populações que se auto-reconhecem e se auto-afirmam como tradicionais norte mineiras é marcada pela existência de um regime agrário coletivo, de relações de trabalho que se estruturam pela reciprocidade entre membros de uma mesma família e de uma mesma coletividade, sobretudo, como patrimônio moral e como lugar de pertencimento. Ela se opõe à lógica capitalista embranquecida e etnicizada do território e do espaço social regional nos tempos atuais. Há a resistência desse povo miúdo que cria, por sua lógica, um território e um espaço social não-capitalista e não-branco dado a sua vinculação a um sistema social que o abarca desde as fronteiras do sistema capitalista, ainda que com ele mantenha vínculos comerciais. Deriva daí a reafirmação das suas autonomias, ainda que em condições mínimas e descontínuas, frente à dominação imposta. Ainda que recorram à migração sazonal em substituição à criação de gado dada a perda das áreas inter-comunitárias ${ }^{7}$ que torna propicio a atualização do padrão produtivo familiar como forma de resistência ao sistema produtivo vigente hegemônico, assim como realizaram seus antepassados.

Ao se colocarem em movimento para concretizar o acesso ao direito territorial coletivo, as gentes miúdas que se auto-afirmaram como Xakriabá, Tuxá, Quilombolas, Vazanteiros, Geraizeiros, Caatingueiros, Veredeiros e Apanhadores de Flores no Semi-árido regional foram desenvolvendo estratégias que romperam a prática da resistência passiva pela

\footnotetext{
${ }^{7}$ Para melhor compreensão das áreas inter-comunitárias recorrentes no Semi-árido norte mineiro vide Oliveira (2017). 
COSTA, J. B. A.

Diversidades e direitos territoriais no semi-árido

adoção de uma resistência ativa ${ }^{8}$. Em todos os movimentos que se alastraram pelo espaço territorial norte mineiro sempre houve a construção de uma imensa trama articulando instituições, entidades, comunidades, pesquisadores e simpatizantes das causas populares. As tramas articuladas construíram redes com extensão nacional e internacional de apoio, o que contribuiu significativamente para a confiança das gentes miúdas e para a eficácia das ações desenvolvidas.

Todas as comunidades que se visibilizaram requerendo o direito territorial no Semi-árido regional estão articuladas em um movimento denominado de Articulação Rosalino de Povos e Comunidades Tradicionais do Norte de Minas. E, na compreensão de que seus direitos coletivos só se concretizarão se desenvolverem ações políticas, essas gentes passaram a ocupar espaços de fala e de definição de políticas públicas, como soi ser a Comissão Nacional de Povos e Comunidades Tradicionais e a Comissão Estadual de Povos e Comunidades Tradicionais, ambas construída com a agência das tradicionalidades norte mineiras.

Desde o denominado Massacre de Rosalino, ocorrido em 12 de fevereiro de 1987 quando alguns Xakriabá, dentre eles sua principal liderança Rosalino foram assassinados por disputa de terras, esses indígenas estabeleceram a estratégia da re-ocupação das terras ancestrais e tradicionalmente ocupada e o enfrentamento com os fazendeiros que os circundam ${ }^{9}$. A compreensão dessa estratégia por parte de outros grupos sociais alastrou-se regionalmente. Assim, os Tuxá, quilombolas, vazanteiros, geraizeiros, caatingueiros, veredeiros e apanhadores de flores têm auto-demarcado e re-ocupado as terras legadas por seus antepassados para forçar a negociação com fazendeiros, empresas de agronegócio,

\footnotetext{
${ }^{8}$ Os caatingueiros norte mineiros são descendentes de portugueses que se fixaram na região no século XVIII e de italianos que se estabeleceram no Norte de Minas no escopo da migração internacional para embranquecer a população brasileira. Eles ocuparam as encostas da Serra do Espinhaço, denominada regionalmente como Serra Geral em decorrência da existência endêmica de malária. A lógica econômica dessa categoria étnica é distinta das outras categorias tradicionais existentes no espaço regional e a estratégia recorrente é a vinculação ao mercado nacional. Não há luta por direito territorial.

9 Três lideranças Xakriabá foram brutalmente assassinadas, tendo como motivo da violência a ganância dos grileiros sobre as terras dos Indígenas. Na madrugada daquele dia quinze homens fortemente armados comandados por Francisco de Assis Amaro, conhecido grileiro de terras do Norte de Minas Gerais, invadiram a aldeia Sapé e atacaram a casa do líder Xakriabá Rosalino Gomes de Oliveira assassinando três pessoas: Rosalino, José Pereira Santana e Manoel Fiúza da Silva. Anizia Nunes de Oliveira (esposa de Rosalino) ficou gravemente ferida. Esta ação aconteceu quando a família de Rosalino estava dormindo e não tiveram nenhuma chance de se defender. Vide Santa Rosa e Anaya (2016, p. 13)
}

Revista Cerrados, Montes Claros/MG, v.16, n. 1, p. 183-203, jan./jun.-2018 
órgãos públicos, como o Instituto Estadual de Floresta, por exemplo, tendo o Ministério Público e a Justiça Agrária como mediadores.

Outra estratégia, a partir do assento de representantes da Articulação Rosalino na Comissão Nacional para o Desenvolvimento Sustentável de Povos e Comunidades Tradicional foi a entrada, neste contexto, da Secretaria do Patrimônio da União que vem desenvolvendo estudos das áreas a ela vinculada nas margens do Rio São Francisco e destinando, por meio de Termo de Autorização de Uso Sustentável (TAUS), cessão de posse aos vazanteiros e pescadores.

No caso de quilombolas e apanhadores de flores diversas re-ocupações de suas áreas têm ocorrido contra unidades de conservação que foram criadas sobrepondo-se ao território tradicionalmente ocupado, em decorrência das relações de interdependência com o ambiente que essas gentes mantiveram historicamente. Para atender ao requisito de reservas florestais de empreendimentos capitalistas, o Estado de Minas Gerais tem, recorrentemente, criado tais unidades em territórios historicamente ocupados por comunidades tradicionais. As re-ocupações e os enfrentamentos têm propiciado a permanência dessas gentes em seus territórios e, em alguns casos, conseguido a desafetação das unidades dada ação do Ministério Público Federal e do Ministério Público Estadual em favor das comunidades tradicionais em lutas territoriais.

No caso dos geraizeiros, algumas estratégias específicas foram construídas. Essa categoria étnica perdeu parte significativa do território com o processo de reflorestamento com maciços de eucaliptos nas chapadas, áreas inter-comunitárias de manejo, principalmente para a solta do gado. E, consequentemente, a perda das nascentes de diversos cursos d'água dada a altíssima absorção do precioso líquido pelos eucaliptos.

Sua primeira estratégia, depois de diversos enfrentamentos com as empresas reflorestadoras, foi apresentar ao Governo do Estado uma proposta de reconversão florestal, dado que o arrendamento das terras reflorestadas havia acabado. Promoveram a primeira autodemarcação do território tradicional, empates e, finalmente, a retomada das chapadas. Em seguida, após muitas lutas, as chapadas da Comunidade Geraizeira de Vereda Funda no município de Rio Pardo de Minas teve parte de sua área destinada à comunidade com a criação pelo Instituto Nacional de Colonização e Reforma Agrária, por meio de sua Superintendência em Minas Gerais de um Projeto de Assentamento Agroextrativista - PAE, por lei votada na Assembléia Legislativa. 
A segunda estratégia geraizeira foi desenvolvida por diversas comunidades situadas no entorno da Chapada do Areião, nas divisas dos municípios de Rio Pardo de Minas, Vargem Grande, Indaiabira e São João do Paraíso. Essa chapada é responsável pela recarga hídrica de diversos cursos d'água e em suas encostas situam-se diversas comunidades que a utilizam como espaço inter-comunitário de solta de gado, de extrativismo de frutos, plantas medicinais e lenha. Com o início da derrubada da vegetação nativa, as mulheres se uniram e conseguiram barrar o trabalho dos tratores com a estratégia do empate. Seus maridos e filhos encontravam-se em migração sazonal para prover recursos financeiros para viabilizar a reprodução da família e coube a elas o enfrentamento. Outros enfrentamentos ocorreram, não apenas com a empresa, mas com agentes públicos da administração municipal e estadual que se posicionaram a favor da empresa reflorestadora. Resulta da ação das gentes dessas comunidades a criação de uma Reserva de Desenvolvimento Sustentável que só foi efetivada após uma greve de sede e fome de diversas mulheres e homens das comunidades e de alguns assessores de sua luta em frente ao Palácio do Planalto em Brasília - DF. Não era a melhor solução, dada a perda da autonomia produtiva com a submissão de qualquer atividade depende de monitoramento por órgão ambiental, mas foi a opção possível.

A criação de uma lei municipal de proteção das nascentes foi a estratégia adotada pela Comunidade Geraizeira de Sobrado em Rio Pardo de Minas que dessa forma conseguiu, do ponto de vista legal, assumir o manejo do território, retirar eucaliptos da chapada de uso inter-comunitário e ver o lençol freático voltar a verter maior volume de água nos cursos e retornar as nascentes a seus lugares originais.

E, por fim, diante do risco da falência do sistema de produção por falta, absoluta, de água, dado o secamento das nascentes e a erosão acelerada das bordas da chapada, a Comunidade do Moreira, em seguida à auto-demarcação do seu território, entrou com representação na Justiça local requerendo a parcela de seu território expropriado para a implantação de maciço de eucalipto. O processo de luta que vem desenvolvendo a consciência da possibilidade de finitude da vida no território legado pelos antepassados começa a ser compartilhado por outras comunidades do entorno da chapada, dado que suas nascentes também foram afetadas. Devido à lentidão na operação do direito, essa estratégia é de longo prazo e ainda não surtiu resultado, embora sua gente, cada vez mais, vem angariando apoio de órgãos de governo, entidades e pessoas sensíveis às causas populares. Ampliando, assim, a 
trama de relações para dar sustentação à luta travada com a reflorestadora que, na atualidade, tem o domínio da terra da chapada, que é por todos considerada a chapada das águas.

Em todas as estratégias de acesso ao território expropriado objetivou-se garantir a permanência da historicidade de cada comunidade em sua forma plena de reprodução da vida material de cada membro e da coletividade como um grupo formador da nacionalidade brasileira. Resulta da concretização de domínio sobre o território comunitário a existência de obstáculos e vantagens.

No primeiro sentido, a perda da autonomia da coletividade sobre seu território com a tutela do Estado quando vinculado à uma das possibilidades de convivência humana com o ambiente protegido em unidades de conservação. Há a submissão do manejo sobre o qual é imposto limites sob a observância de algum funcionário do governo seja federal ou estadual. E no caso da lei municipal viabilizada pela Comunidade Geraizeira do Sobrado, a não regulamentação da mesma, ainda que os membros da comunidade mantenham vigilância e controle sobre o território.

E no segundo sentido, as vantagens, o Projeto de Assentamento Agroecológico propicia à comunidade ampla autonomia, dado ser gerenciado por um conselho composto por membros da comunidade que aprovaram e vincularam ao projeto normas de utilização e manejo, além de estar vinculado ao Instituto Nacional de Colonização e Reforma Agrária que transfere recursos orçamentários que são administrados pelo conselho por meio de definições da coletividade.

O que marca esta movimentação é a entrada em cena de populações vivendo em comunidades que reivindicam não apenas a terra, mas o direito de serem reconhecidas como detentoras de uma cultura própria, uma maneira diferenciada de ver e agir no mundo. Que possuem uma economia que considera outros valores que não somente o lucro ou a exploração do trabalho, um jeito diferente de usar e de manejar os ambientes cujo lastro é o conhecimento construído desde a ancestralidade. Onde a convivência com o Semi-árido se dá a partir do reconhecimento da sociobiodiversidade sertaneja e do conhecimento associado aos potenciais e limites dos ecossistemas regionais.

Para finalizar, o Semi-árido Mineiro é uma região que, a partir dos anos 2000, reemerge no cenário nacional a partir da resistência ativa dos povos do lugar aos processos de desterritorialização para a agricultura e na luta pela convivência com os potenciais culturais e ecossistêmicos do sertão médio sanfranciscano. Os interesses que esses povos enfrentam 
agora não são somente os dos antigos latifúndios, são interesses que vem sendo encetados pelos grandes conglomerados econômicos, do capital agroindustrial e financeiro, da mineração, da siderurgia, que se movem em órbita planetária, subjugando governos nacionais, estaduais e locais. Por outro lado, como o enfrentamento é local, as gentes miúdas desenvolvem e disseminam iniciativas e práticas produtivas de convivência com os ecossistemas regionais e com os processos de mudanças climáticas cada vez mais incisivos, construindo estratégias de enfrentamento, parando máquinas que destroem os cerrados, as caatingas e as matas secas, cotidianamente enfrentam grileiros e políticos que dominam a máquina estatal. O enfrentamento exige muitas frentes de ação com estratégias sempre inovadas, muita inteligência e, principalmente, a capacidade de diálogos com aqueles que, também em distintas órbitas, em distintos espaços, local, nacional e internacional, buscam sinergias e convergências em busca da sustentabilidade planetária.

E como cantam nossas gentes em suas festividades:

Temos pólvora chumbo e bala, Nós queremos é guerrear.

\section{CONSIDERAÇÕES FINAIS}

No espaço do Semi-árido brasileiro ao longo de sua história diversos grupos humanos construíram formas distintas de apropriação do espaço e organizaram seus sistemas de produção fixando na terra diversas camadas com dimensões sociais, culturais e simbólicas, propiciando fundamentar, por uma razão histórica, suas identidades singulares e as bases para a reivindicação política do direito territorial coletivo emergido na Constituição de 1988.

A par de um modelo analítico, constitutivo do olhar antropológico, transito pelo espaço dessa região do Brasil que contém os estados nordestinos e a porção norte do estado de Minas Gerais para colocar na cena argumentativa as diversas etnicidades reivindicando os direitos territoriais por serem grupos que contribuíram, significativamente, para dar corpo à nacionalidade plural brasileira. Ao mesmo tempo, apresento as estratégias construídas e implementadas por diversas comunidades norte mineiras que se afirmam tradicionais e que são reconhecidas como tais pelos governos federal e do Estado de Minas Gerais.

É por meio dessas estratégias, diversas, que, organizadas política e coletivamente na Articulação Rosalino de Povos e Comunidades Tradicionais que as mesmas têm 
conseguido, na luta contra fazendeiros, empresas de agro-negócio e empresas silvicultoras, retomar os territórios legados por seus ancestrais, ou partes deles, e reafirmado sistemas produtivos plurais para garantir a reprodução material de cada família e de cada coletividade, dada a organização que os une em uma totalidade social, bem como, vincular-se ao sistema produtivo internacional pela comercialização de diversos itens da produção realizada.

Esse é um processo recorrente e, em muitas localidades, emergente, mas cada coletividade se vê amparada por uma rede sociotécnica, por estudiosos e instituições e pela organização que os representa politicamente na luta pelos direitos territoriais coletivos, como definido na Constituição de 1988. Suas negociações com os governos federal e estadual, em Minas Gerais, a votação de lei, de iniciativa popular, na câmara municipal e a entrada com representação na Comarca do município contra a empresa reflorestadora responsável pelo fenecimento dos três cursos de água, que propiciou historicamente a constituição de sistema produtivo policultor, inviabilizando a vida da gente pequena. Estas são conquistas para a efetivação do direito coletivo que essas gentes buscam tornar real.

\section{REFERÊNCIAS}

ALMEIDA, Alfredo Wagner Berno de. Terras tradicionalmente ocupadas: processos de territorialização e movimentos sociais. Em Revista Brasileira de Estudos urbanos e regionais 6 (1), Mai 2004, p. 9-32.

ARRUTI, José Maurício Andion. A Emergência dos "remanescentes": notas para o diálogo entre indígenas e quilombolas. Em Mana 3 (2), 1997, p. 7-38.

BRASIL. Política Nacional para o Desenvolvimento Sustentável de Povos e Comunidades Tradicionais. Em Decreto 6.040/2007. Brasília, Diário Oficial da União, 2007.

CHAGAS, Afonso Maia das. Direitos territoriais: identidades, pertencimentos e reconhecimento. Em Revista sobre acesso à Justiça e Direitos nas Américas 1 (1), 2017, p. $182-201$.

COSTA, João Batista de Almeida. Cultura sertaneja: a conjugação de lógicas diferenciadas. Em SANTOS, Gilmar Ribeiro dos (Org.). Trabalho, Cultura e Sociedade no Norte/Nordeste de Minas: Considerações a partir das Ciências Sociais. Montes Claros: Best Comunicação e Marketing, pp. 77-98, 1997.

COSTA, João Batista de Almeida. A (des)invisbilidade dos Povos e Comunidades Tradicionais: A produção da identidade, do pertencimento e do modo de vida como estratégia para efetivação de direito coletivo. Em: GAWORA, D.; IDE, M. H. de S.; BARBOSA, R. S. 
(Orgs.). Povos e Comunidades Tradicionais no Brasil. $1^{a}$. ed. Montes Claros: Editora Unimontes, 2011, p. 51-68.

COSTA, João Batista de. A invenção de sujeitos de direito e processos sociais: Povos e Comunidades Tradicionais no Brasil e no Norte de Minas Gerais. Belo Horizonte: Initia Via, 2015. 84 p. Coleção Direito e Diversidade 5.

COStA SILVA, René Marc. Por onde o Povo Anda... A Construção da Identidade Quilombola dos Negros de Rio das Rãs. Brasília: PPGH / UnB, 1998. Tese.

CUNHA, Euclides. Os Sertões. Brasília: Editora da UnB; Rio de Janeiro: FUNDAR / Biblioteca Nacional, 2015. 623 p.

FIGUEIREDO, André Videira de. O Caminho quilombola: sociologia jurídica do reconhecimento étnico. Curitiba: Apris. 2001. 211 p.

GUIMARÃES ROSA, João. Grande Sertão: Veredas. Rio de Janeiro: Nova Fronteira, 1986. $538 \mathrm{p}$.

HONNETH, Axel. Luta por reconhecimento: a gramática moral dos conflitos sociais. São Paulo: Ed. 34, 2003. 291 p.

LITTLE, Paul Elliot. Territórios Sociais e povos tradicionais no Brasil: por uma antropologia da territorialidade. Em Anuário Antropológico, 2002/2003, 2005, pp. 251-290.

LOPES, Esmeraldo. Caatingueiros e Caatinga: a agonia de uma cultura. Maceió: Grafipel, $2012.532 \mathrm{p}$.

OLIVEIRA, Moisés Dias. Auto-definição identitária e territorial entre os geraizeiros do Norte de Minas: O caso da Comunidade de Sobral. Brasília: Centro de Desenvolvimento Sustentável / UnB, 2017. Dissertação.

PARAJULI, Pramod. Ecological Ethnicity in the Making: Developmentalist Hegemonies and Emergent Identities in India. Em: Identities, 3(1-2), 1996, pp. 15-59.

RIBEIRO, Darcy. O povo brasileiro: a formação e o sentido do Brasil. São Paulo: Companhia das Letras, 1995. 476 p.

RIGATO, Valney Dias. Por uma geografia de / em transição: r-existência e (re)habitação dos geraizerios no Médio Vale do Rio Guará, São Desidério, BA. Goiânia: PPGEO / UFG, 2017. Tese.

SANTA ROSA, Helen e ANAYA, Felisa Cançado. A raiz que sustenta nossa identidade. Em Agriculturas, 13 (1), 2012, p. 12-17.

SILVA, Tomaz Tadeu. A produção social da identidade e da diferença. Em Identidade e diferença: a perspectiva dos Estudos Culturais. Petrópolis: Vozes, 2000, p. 73-102. 
SOUZA, Laura Mello e. Os desclassificados do ouro: a pobreza mineira no século XVIII. São Paulo: Graal, 1986. 323 p.

PARK, R. E. A comunidade urbana como configuração social e ordem moral. Em PIERSON, Donald (Org). Estudos de ecologia humana. São Paulo: Livraria Martins, 1948, p. 127-142.

\section{Autores}

João Batista de Almeida Costa - Possui Graduação em Ciências Sociais pela Universidade Federal de Minas Gerais (UFMG), Mestrado e Doutorado em Antropologia Social, ambos cursados na Universidade de Brasília (UnB). Atualmente é Professor do Departamento de Política e Ciências Sociais e do Programa de Pós-Graduação em Desenvolvimento Social da Universidade Estadual de Montes Claros (UNIMONTES).

Artigo recebido em: 07 de dezembro de 2017.

Artigo aceito em: 29 de maio de 2018.

Artigo publicado em: 30 de junho de 2018. 